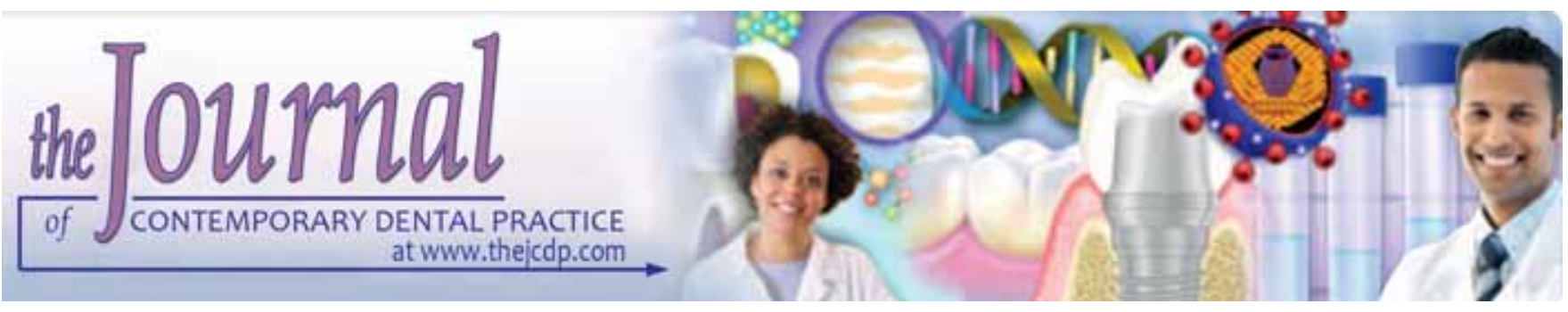

\title{
Retrospective Study of 25 Cases of Keratocystic Odontogenic Tumor: Epidemiology and Treatment
}

\author{
Juliana L Schussel, Roberta T Stramandinoli, Jose Luis Dissenha, Lucia FC Avila, Laurindo M Sassi
}

\begin{abstract}
Aim: Keratocystic odontogenic tumor (KOT) is a benign odontogenic neoplasm with locally aggressive behavior and high recurrence rates. It is associated with nevoid basal cell carcinoma syndrome which usually has a more rapid growth. The aim of the study is to report the experience of our service on diagnosis and treatment of KOT.
\end{abstract}

Materials and methods: Twenty-five cases of KOT were diagnosed between the years of 1989 and 2006. Demographic data was collected as well as diagnose and treatment.

Results: Fifty-six percent were female with a mean age of 33 years old. Seventy percent occurred in mandibula and all received surgical treatment, associate or not with adjuvant therapy, such as cryotherapy and Carnoy's solution. Recidive was observed in $48 \%$ of cases with a mean period of time of 18 months.

Conclusion: Our data analysis showed the importance of previous diagnosis before enucleation procedure and long-term follow-up for recurrence early detection. Recurrence incidence is more frequent on first year after diagnosis.

Clinical significance: KOT is a benign tumor with local aggressive behavior and therefore its treatment must consider the high index of recidive. Reports of protocol treatment should raise new discussion to decrease recurrence rates.

Keywords: Keratocyst, Odontogenic tumor, Keratocystic odontogenic tumor.

How to cite this article: Schussel JL, Stramandinoli RT, Dissenha JL, Avila LFC, Sassi LM. Retrospective Study of 25 Cases of Keratocystic Odontogenic Tumor: Epidemiology and Treatment. J Contemp Dent Pract 2011;12(2):100-103.

Source of support: Nil

Conflict of interest: None declared

\section{INTRODUCTION}

The odontogenic keratocyst (OKC), first described in 1956 by Philipsen ${ }^{1}$ as an odontogenic cyst with keratinized epithelium, was differentiated from other odontogenic lesions because of its particular characteristics, such as high recurrence and specific histopathological features. Its biological behavior, after numbers of immunohistochemical and molecular studies, lead the WHO Working Group, in 2005 to consider the parakeratinizing variant to be a cystic neoplasm, using, for that reason, a more descriptive term 'keratocystic odontogenic tumor' (KCOT). ${ }^{2}$ The discovery of chromosomal abnormalities and genetic alterations, such as mutation of the PTCH gene, reinforce the new classification. ${ }^{3,4}$

The same controversy that has been discussed about the KCOT classification occurred about its treatment. The early reports on literature about the KCOT recurrence showed that $50 \%$ of the lesions recidivate after only 6 months of follow-up. Exclusive enucleation was obviously not enough to prevent the KCOT from recur. Many adjuvant treatments have been proposed since then and, here, we analyze the epidemiology and efficiency of the treatments used by our service.

\section{MATERIALS AND METHODS}

Twenty-five cases of KCOT, diagnosed in the service of oral and maxillofacial surgery at the Erasto Gaertner Hospital, Curitiba, Brazil, between the years of 1989 and 2006, were retrospectively studied. Clinical and radiographic features were reviewed and follow-up data were obtained. All lesions fulfilled the criteria for KCOTs as defined by the World Health Organization: Cystic lesion lined by a regular parakeratinized stratified squamous epithelium, with a well-defined, often palisaded, basal layer of columnar or cuboidal cells. The parakeratotic layers often have a corrugated surface. For all cases, a previous biopsy was perfomed. The treatment of choice was usually enucleation. Some cases were conducted with adjuvant therapy, such as cryotherapy using liquid nitrogen at $-80^{\circ} \mathrm{C}$ 
or application of Carnoy's solution (absolute alcohol, $6 \mathrm{ml}$; chloroform, $3 \mathrm{ml}$; glacial acetic acid, $1 \mathrm{ml}$; ferric chloride, $1 \mathrm{gm})$. In some cases, an unspecific diagnose of odontogenic cyst lead to a more conservative treatment on first surgery. Two cases were associated with the nevoid basal cell carcinoma syndrome. Both patients presented several basal cell carcinoma and also presented facial features of the syndrome.

All the patients were followed by clinical and radiographical examinations for a period ranging from 2 to 7 years after enucleation. Recurrence rates were analyzed and compared in view of site of involvement and methods of treatment.

\section{RESULTS}

The results were analyzed considering gender and age distribution, tumor location, clinicopathological findings and recurrence and the association with the nevoid basal cell carcinoma syndrome as seen in Table 1.

\section{Gender and Age Distribution}

During the past 17 years, twenty-five KCOT were diagnosed at the service of oral and maxillofacial surgery of the Erasto Gaertner Hospital, Curitiba/Brazil. Eleven (44\%) occurred in males and 14 (56\%) in females; the male to female ratio was $1: 1.2$. Patients ranged in age at the time of diagnosis from 10 to 65 years, with a mean age of 33 years old.

\section{Tumor Location}

Three patients had multiple lesions, with a total of 28 lesions analyzed. Twenty-one cases (75\%) occurred in the mandible, from which 17 (80\%) in the molar and ramus area and only $3(20 \%)$ cases occurred on the anterior mandible. Seven (25\%) cases occurred in the maxilla.

\section{Clinicopathological Findings and Recurrence}

The recurrence rate observed was $48 \%$. The time between first treatment and recidive ranges from 9 to 48 months, with ratio of 18 months. From the 25 cases analyzed, the mean period of follow-up was of 3 years, ranging from 12 months to 7 years. The treatment of choice on 18 cases was exclusive enucleation, seven cases received adjuvant treatment as cryotherapy or use of Carnoy's solution.

\section{Nevoid Basal Cell Carcinoma Syndrome (NBCCS)}

Two cases of NBCCS were present in our series. The first case was a 12-year-old boy that had a medulloblastoma at the age of 1 year that was treated with radiotherapy. Later developed multiple basal cell carcinomas (BCC) and KCOT. Finally, the patient developed a medulloblastoma recurrence and died at the age of 18 years. The second case was a 29year-old woman who presented multiple KCOT and had never before been diagnosed with NBCCS. After the KCOT manifestations, the patient was referred with multiple BCC

\begin{tabular}{|c|c|c|c|c|c|c|c|}
\hline Case & $\begin{array}{c}\text { Age } \\
\text { (years) }\end{array}$ & Sex & Location & Treatment & $\begin{array}{l}\text { Time of } \\
\text { recurrence (months) }\end{array}$ & $2^{\circ}$ treatment & $\begin{array}{l}\text { Follow-up } \\
\text { (years) }\end{array}$ \\
\hline 1 & 28 & $\mathrm{~F}$ & Post MX & S + Cryo & 30 & $\mathrm{~s}$ & 5 \\
\hline 2 & 30 & $M$ & Post MD & $\mathrm{S}$ & - & & 5 \\
\hline 3 & 27 & $\mathrm{~F}$ & Post MD & $\mathrm{S}$ & 9 & S + Cryo & 5 \\
\hline 4 & 54 & $\mathrm{~F}$ & Post MD & $\mathrm{S}$ & 10 & S + Cryo & 4 \\
\hline 5 & 61 & M & Post MD & $\mathrm{S}$ & 25 & $\mathrm{~S}+$ Cryo & 3 \\
\hline 6 & 32 & $\mathrm{~F}$ & Post MD & $\mathrm{S}$ & 26 & $\mathrm{~S}+$ Cryo & 4 \\
\hline 7 & 44 & $\mathrm{~F}$ & Post MD & $\mathrm{S}$ & - & & 7 \\
\hline 8 & 35 & $\mathrm{~F}$ & Post MX & $\mathrm{S}$ & 41 & S + Carnoy & $21 / 2$ \\
\hline 9 & 48 & $\mathrm{~F}$ & Post MD & $\mathrm{S}$ & - & & 6 \\
\hline 10 & 24 & $\mathrm{~F}$ & Post MD & $\mathrm{S}$ & 18 & S + Cryo & 5 \\
\hline 11 & 65 & $M$ & Post MD & $\mathrm{S}$ & - & & 3 \\
\hline 12 & 20 & $M$ & Post MD & $\mathrm{S}+$ Cryo & 17 & S + Carnoy & $31 / 2$ \\
\hline 13 & 41 & $\mathrm{~F}$ & Post MD & $\mathrm{S}+$ Cryo & - & & 4 \\
\hline 14 & 12 & $\mathrm{~F}$ & Post MX & $\mathrm{S}$ & 12 & S + Carnoy & 3 \\
\hline 15 & 20 & $M$ & Post MD & $\mathrm{S}$ & 10 & S + Carnoy & 3 \\
\hline 16 & 10 & $M$ & Post MX & $\mathrm{S}$ & - & & 3 \\
\hline 17 & 64 & $M$ & Post MX & $\mathrm{S}$ & - & & 3 \\
\hline 18 & 12 & $M$ & $\mathrm{MX}, \mathrm{MD}$ & $\mathrm{S}$ & 48 & S + Cryo & GGS \\
\hline 19 & 29 & $M$ & Ant. MD & S + Carnoy & & & GGS \\
\hline 20 & 54 & $\mathrm{~F}$ & Post MD & C & - & & $21 / 2$ \\
\hline 21 & 15 & $M$ & Ant. MD & S + Carnoy & - & & 2 \\
\hline 22 & 43 & $\mathrm{~F}$ & Post MD & $\mathrm{S}$ & 12 & S + Carnoy & 4 \\
\hline 23 & 18 & $\mathrm{~F}$ & Post MD & $\mathrm{S}$ & 12 & S + Carnoy & 2 \\
\hline 24 & 26 & M & MD & S + Cryo & - & & 5 \\
\hline
\end{tabular}

F: Female; M: Male; MD: Mandible; MX: Maxilla; Ant: Anterior area; Post: Posterior area; Cryo: Cryotherapy; Carnoy: Carnoy's solution; S: Surgery. 
and a glioma. She had many complications due to the brain tumor and died 2 years after its diagnose. Both patients presented bifid ribs, frontal prominence, hypertelorism and learning difficulties.

\section{DISCUSSION}

Our results showed a slightly predilection for females with a male to female ratio of $1: 1.2$, in contrast to most reports on literature. Maurette et $\mathrm{al}^{5}$ also found a male to female ratio of 1:2.1 in a series of 30 cases from Brazil. The age distribution in our series was the third decade of life, in agreement with most reports on literature.

The mandible was found to be the most common site of KCOT, occurring in 70\% (17) of cases, which was in agreement with findings of other studies. The most common mandibular site was the posterior area. The posterior area was also the most commonly affected part of the maxilla, which had $30 \%$ of cases.

NBCCS was first described as a syndrome in 1960 by Gorlin and Goltz. ${ }^{4}$ It is an autosomal dominant disorder with manifestations that can affect many organs. The diagnosis can be made clinically, and it is characterized by a series of associated manifestations, the most common are multiple KCOT and cutaneous basal cell carcinomas, but also can present cardiac disturbances, frontal and parietal prominence, marked superciliary arches, hypertelorism, skeletal alterations, such as vertebrae problems and bifid ribs, neurological alterations, such as calcification of the cerebral falx, learning difficulties and other disturbances that can be associated with other malignant neoplasia. The KCOT occurs in 65 to $100 \%$ of the cases of NBCCS and most of times precede basal cell carcinomas, being an important factor for early diagnosis of the syndrome. Our series had two cases of NBCCS, with more than one lesion, in both maxilla and mandible, with fast recurrence. Besides the KCOT lesions, both present other syndrome manifestations, such as basal cell carcinomas, bifid ribs, frontal prominence, learning difficulties and neurological lesions. One of the cases was diagnosed with NBCCS with 12 years, and the other patient with 29 years, by the time when her first KCOT was detected.

The first author to suggest the neoplastic nature of the KCOT was Toller (1967), based on its clinical behavior. ${ }^{6}$ WHO's reclassification reinforces that it should be managed as an aggressive lesion and not as a simple cyst. Many review studies about KCOT treatment shows that an aggressive approach is more likely to reduce the risk of recurrence. ${ }^{7}$ Our study showed a recurrence rate of $50 \%$, and when only enucleation was performed, it ranged $41 \%$ of the cases. A biopsy was taken, of each case, before the definitive treatment was carried out, and in some cases the first diagnose was not definitive and the treatment of choice was enucleation. When the biopsy diagnose was of KCOT, the treatment was enucleation and cryotherapy, or in some cases Carnoy's solution. Application of Carnoy's solution was made after enucleation, isolating the surgical area by 5 minutes; the cryotherapy was applied on surgical area, also after enucleation. The interval from time of treatment to time of recurrence ranged from 9 to 48 months, with 18 months ratio. Different from our study, previous reports have shown a recurrence 41 years after treatment, which points to the importance of long time follow-up. ${ }^{8}$ We observed a high index of recurrence on patients that received cryotherapy, when compared with Carnoy's solution.

The main causes for such a high recurrence rate are associated with the formation of daughter cysts that can be left behind during surgery and also with the fine lining epithelium that can tear apart during surgery. Studies showed that when the lesion can be removed as a unique piece, the recurrence rate is lower. The use of chemical cautery, such as Carnoy’s solution, after enucleation, aggressive curettage of bony walls, cryotherapy, peripheral ostectomy or even a radical resection has been proposed by many authors in the attempt to remove any remaining epithelium. Some authors also suggest also the performance of a marsupialization before enucleation to reduce tumor size.

The KCOT is originated from the reminiscent of the dental lamina, and its proliferative potential has been demonstrated not only on the epithelium but also on the mesenchimal component, suggesting the cystic capsule also participate on the growing process of the tumor. This discovery points to an aggressive behavior and invasiveness potential and also the recurrence may reflect the nature of the tumor.

In most cases, recurrence manifests itself within the first 5 years, but life-long follow-up schedule is recommended, regardless treatment. ${ }^{9}$ The recurrent KCOT should be treated more aggressively than the primary counterpart. Resection can be considered for the treatment, but it can lead to a poorer oral function.

The marsupialization is also a method proposed by many authors in the treatment of KCOT. ${ }^{10,11}$ It implies the exteriorization of a cyst by resecting a portion of its wall to adjacent soft tissue creating a pounch. Pogrel and Jordan (2004) present a case series of 10 patients successfully treated with marsupialization, with no recurrence report after 2.8 years of follow-up. ${ }^{10}$ Once the KCOT recurrence is usually observed 5 years after treatment, this kind of procedure just should be considered in very well-indicated cases. The patient compromising with the treatment is very 
important for recurrence early detection. Long-term followup data made by Stoelinga (2001) reveal a recurrence rate of $1 \%$ over a 25 -year period with marsupialization treatment. ${ }^{12}$

\section{CONCLUSION}

The treatment of choice should take into account patient age, tumor size and location, soft tissue involvement, previous treatment and clinical, radiographic and histological features.

\section{CLINICAL SIGNIFICANCES}

Our data analysis showed the importance of previous diagnoses, before enucleation procedure and also the need of long-term follow-up for recurrence early detection. Also, that is important to evaluate the patient closely for the first year when there is more recurrence incidence. All patients in this study are still in follow-up.

\section{REFERENCES}

1. Philipsen HP. Om keratocystedr (Kolesteratomer) and kaeberne. Tandlaegebladet 1956;60:963-71.

2. Barnes L, Eveson JW, Reichart P, Sidransky D, et al. Pathology and genetics of head and neck tumours. Lyon: IARC Press. WHO classification of tumours series 2005.

3. Barreto DC, Gomez RS, Bale AE, Boson WL, De Marco L. PTCH gene mutations in odontogenic keratocysts. J Dent Res 2000;79:1418-22.

4. Johnson RL, Rothman AL, Xie J, et al. Human homolog of patched, a candidate gene for the basal cell nevus syndrome. Science 1996;272:1668-71.

5. Maurette PE, Jorge J, de Moraes M. Conservative treatment protocol of odontogenic keratocyst: A preliminary study. J Oral Maxillofac Surg 2006;64:379-83.

6. Toller P. Origin and growth of cysts of the jaws. Ann R Coll Surg Engl 1967;40:306-36.

7. Zhao YF, Wei JX, Wang SP. Treatment of odontogenic keratocysts: A follow-up of 255 Chinese patients. Oral Surg Oral Med Oral Pathol Oral Radiol Endod 2002;94:151-56.

8. Crowley TE, Kaugars GE, Gunsolley JC. Odontogenic keratocysts: A clinical and histologic comparison of the parakeratin and orthokeratin variants. J Oral Maxillofac Surg 1992;50:22-26.

9. Gonzalez-Alva P, Tanaka A, Oku Y, et al. Keratocystic odontogenic tumor: A retrospective study of 183 cases. J Oral Sci 2008;50:205-12.

10. Pogrel MA, Jordan RC. Marsupialization as a definitive treatment for the odontogenic keratocyst. J Oral Maxillofac Surg 2004;62:651-55; discussion 655-56.

11. Pogrel MA. Decompression and marsupialization as a treatment for the odontogenic keratocyst. Oral Maxillofac Surg Clin North Am 2003;15:415-27.

12. Stoelinga PJ. Long-term follow-up on keratocysts treated according to a defined protocol. Int J Oral Maxillofac Surg 2001;30:14-25

\section{ABOUT THE AUTHORS}

\section{Juliana L Schussel}

Oral Pathologist, Department of Oral and Maxillofacial Surgery, Erasto Gaertner Hospital, Parana, Brazil

\section{Roberta T Stramandinoli}

Dentist, Department of Oral and Maxillofacial Surgery, Erasto Gaertner Hospital, Parana, Brazil

\section{Jose Luis Dissenha}

Surgeon, Department of Oral and Maxillofacial Surgery, Erasto Gaertner Hospital, Parana, Brazil

\section{Lucia FC Avila}

Dentist, Department of Oral and Maxillofacial Surgery, Erasto Gaertner Hospital, Parana, Brazil

\section{Laurindo M Sassi}

Chair, Department of Oral and Maxillofacial Surgery, Erasto Gaertner Hospital, Parana, Brazil

\section{CORRESPONDING AUTHOR}

Laurindo M Sassi, Rua Ovande do Amaral, 201, Curitiba-PR, Brazil, Phone: 81520-060, e-mail: sassilm@onda.com.bre 